\section{Dinucleotide repeat polymorphism at the D4S174 locus}

\author{
James L.Weber*, Anne E.Kwitek, \\ Paula E.May and Ann M.Killary ${ }^{1}$ \\ Marshfield Medical Research Foundation, 510 \\ North St. Joseph Avenue, Marshfield, WI 54449 \\ and ${ }^{1}$ University of Texas, M.D.Anderson Cancer \\ Center, Houston, TX 77030, USA
}

Source/Description: A human genomic Sau3AI fragment was cloned into mp19 and selected by hybridization to poly $(\mathrm{dC}$ dA) · poly(dG-dT). The cloned fragment was designated Mfd59. Sequencing of Mfd59 provided the information necessary for polymerase chain reaction primer synthesis. The clone length was $318 \mathrm{bp}$, and the predicted length of the amplified fragment was $183 \mathrm{bp}$.

Primer Sequences: AAGAACCATGCGATACGACT (CA strand); CATTCCTAGATGGGTAAAGC (GT strand).

Frequency: Estimated from 120 chromosomes of unrelated CEPH family grandparents (Caucasians). PIC $=0.86$.

$\begin{array}{llll}\text { Allele(bp) } & \text { Frequency } & \text { Allele(bp) } & \text { Frequency } \\ 195 & 0.01 & 183 & 0.11 \\ 193 & 0.04 & 181 & 0.08 \\ 191 & 0.14 & 179 & 0.14 \\ 189 & 0.06 & 177 & 0.12 \\ 187 & 0.11 & 175 & 0.01 \\ 185 & 0.18 & & \end{array}$

Chromosomal Localization: Assigned to chromosome 4 using DNA templates isolated from panels of somatic cell hybrids.

Mendelian Inheritance: Co-dominant segregation was observed in 15 two generation families.

Other Comments: Conditions for the amplification reactions were as described in the reference except that samples were processed through 27 temperature cycles consisting of $1 \mathrm{~min}$ at $94^{\circ}, 2 \mathrm{~min}$ at $55^{\circ}$ and $2 \mathrm{~min}$ at $72^{\circ}$. Sizes of the alleles were determined by comparison to mp8 DNA sequencing ladders. The most intense band for each allele on the denaturing polyacrylamide gels was used to obtain allele size. The dinucleotide repeat sequence in Mfd59 was of the form (AC) $)_{23} \mathrm{~A}$. The sequence of Mfd59 has been submitted to GenBank.

Acknowledgements: This work was supported by the Marshfield Clinic and NIH grant GM41773. Sue Naylor provided DNA from a chromosome 4-specific hybrid.

References: Weber,J.L. and May,P.E. (1989) Am. J. Hum. Genet. 44, 388-396.

\footnotetext{
* To whom correspondence should be addressed
}

\section{Dinucleotide repeat polymorphism at the D6S87 locus}

\author{
James L.Weber*, Anne E.Kwitek and \\ Paula E.May \\ Marshfield Medical Research Foundation, 510 \\ North St. Joseph Avenue, Marshfield, WI 54449, \\ USA
}

Source/Description: A human genomic Sau3AI fragment was cloned into mp19 and selected by hybridization to poly $(\mathrm{dC}$ dA) · poly(dG-dT). The cloned fragment was designated Mfd47. Sequencing of Mfd47 provided the information necessary for polymerase chain reaction primer synthesis. The clone length was $>280 \mathrm{bp}$, and the predicted length of the amplified fragment was $148 \mathrm{bp}$.

Primer Sequences: ACAGAGTGAGACCGTGTAAC (CA strand); AGAGAAGCATCTCACTTAGT (GT strand).

Frequency: Estimated from 106 chromosomes of unrelated CEPH family grandparents (Caucasians). PIC $=0.53$.

$\begin{array}{llll}\text { Allele(bp) } & \text { Frequency } & \text { Allele(bp) } & \text { Frequency } \\ 155 & 0.01 & 143 & 0.01 \\ 153 & 0.02 & 141 & 0.33 \\ 149 & 0.04 & 139 & 0.02 \\ 147 & 0.53 & 137 & 0.01 \\ 145 & 0.03 & & \end{array}$

Chromosomal Localization: Assigned to chromosome 6 using DNA templates isolated from panels of somatic cell hybrids.

Mendelian Inheritance: Co-dominant segregation was observed in 15 two generation families.

Other Comments: Conditions for the amplification reactions were as described in the reference except that samples were processed through 27 temperature cycles consisting of $1 \mathrm{~min}$ at $94^{\circ}, 2 \mathrm{~min}$ at $55^{\circ}$ and $2 \mathrm{~min}$ at $72^{\circ}$. Sizes of the alleles were determined by comparison to mp8 DNA sequencing ladders. The most intense band for each allele on the denaturing polyacrylamide gels was used to obtain allele size. The dinucleotide repeat sequence in $\mathrm{Mfd} 47$ was of the form (AC) ${ }_{17} \mathrm{~A}$. The sequence of Mfd47 has been submitted to GenBank.

Acknowledgements: This work was supported by the Marshfield Clinic and NIH grant GM41773.

References: Weber,J.L. and May,P.E. (1989) Am. J. Hum. Genet. 44, 388-396.

\footnotetext{
* To whom correspondence should be addressed
} 